\title{
O RITUAL NO ÂMBITO DO LAZER DE UMA PROVA DE MEIA MARATONA
}

\author{
Recebido em: 23/06/2018 \\ Aceito em: 24/01/2019 \\ Cinthia Lopes da Silva \\ Universidade Metodista de Piracicaba (UNIMEP) \\ Piracicaba - SP - Brasil \\ Ana Carolina Capellini Rigoni \\ Universidade Federal do Espírito Santo (UFES) \\ Vitória - ES - Brasil \\ Luciene Ferreira da Silva \\ Universidade Estadual Paulista "Júlio de Mesquita Filho" (UNESP) /Bauru \\ Bauru - SP - Brasil \\ Marcelo de Farias Teixeira \\ Instituto Federal de Educação Ciência e Tecnologia do Norte de Minas Gerais \\ Januária - MG - Brasil
}

RESUMO: Neste estudo o problema investigado diz respeito às corridas de rua, em que os rituais demonstram a riqueza das formas de modus operandi dos vários participantes e grupos, que com objetivos distintos participam de provas de rua como, por exemplo, a meia maratona. Os objetivos foram identificar e analisar os significados e aspectos ritualísticos produzidos pelos corredores durante a participação em uma prova de meia maratona. A corrida de rua tem sido uma das atividades do contexto do lazer de pessoas de diferentes faixas etárias, condição de vida e de gênero. Para alguns, o lazer é um elemento da cultura não levado muito a sério diante de atividades que envolvem as obrigações sociais como o trabalho. No entanto, a partir do lazer podemos identificar particularidades de um grupo ou sociedade. A natureza da pesquisa é qualitativa. Foi realizada revisão de literatura, debate dos textos selecionados entre os investigadores e pesquisa de campo. Uma das pesquisadoras correu a prova de meia maratona e utilizou a técnica de observação participante. A partir das observações realizadas e analisadas identificou-se valores e aspectos constituintes das ações dos corredores: a competição, a honra em defesa da masculinidade e a interação social. Também foi possível observar que na corrida há grupos com interesses diversos e que o componente lúdico estava presente nas manifestações dos corredores observados, talvez pelo fator da corrida nesse caso ser uma ação realizada não como forma de obrigação.

PALAVRAS CHAVE: Atividades de Lazer. Corrida. Cultura. 
ABSTRACT: In this study, the problem investigated refers to the street races, in which the rituals demonstrate the richness of the modus operandi of the various participants and groups, for different reasons, participating in street events such as the half marathon. The objectives of this work were to identify and analyse the meanings and ritualistic aspects produced by the runners during the participation in a half marathon event. Street racing has been one of the activities of the leisure context for people of different age groups, living conditions and gender. For some, leisure is an element of culture not taken very seriously in the face of activities involving social obligations, such as work. However, based on leisure studies, we can identify particularities of a group or society. The nature of this research is qualitative. Literature review, discussion of selected texts among researchers and field research were carried out. One of the researchers ran the half marathon race and used the participant observation technique. From the observations made and analysed, values and constituent aspects of runners actions were identified: competition, honour in defence of masculinity and social interaction. It was also possible to observe that in the race there are groups with different interests and that the play component was present in the manifestations of the observed runners, perhaps because the race in this case is an action performed not as a form of obligation.

KEYWORDS: Leisure Activities. Running. Culture.

\section{Introdução}

Mauss e Hubert (2005), ao elaborarem a teoria geral da magia, denominaram de mágico, o indivíduo que efetua atos mágicos, mesmo quando este não é um profissional. Os atos mágicos são por sua vez, ritos, e comportam um mínimo de representação que é, segundo Mauss (2003, p.97), “a representação de seu efeito”. São classificados como mágicos os atos jurídicos, as técnicas, os atos religiosos. Assim, para os autores, seriam mágicos o sacerdote, a benzedeira, o pajé de uma tribo indígena, mas também o médico, o alquimista, e os diferentes sujeitos que realizam em seu cotidiano certos ritos/rituais que pressupõem uma técnica específica e que são, sobretudo, representativos ou significativos para eles próprios pelo seu efeito.

Neste sentido, o efeito, ou como Mauss (2003) prefere chamar, a eficácia, é um elemento fundamental na análise do ritual. Um rito mágico é sempre eficaz, mas sua 
eficácia nem sempre é "mecânica" ou mensurável. O que faz as pessoas alimentarem a crença nos atos mágicos é, portanto, a sua eficácia simbólica e a tradição que dela emerge.

Outro elemento presente no ritual é a “transformação”. Segundo Mauss (2003), o rito faz do indivíduo outro homem. É o caso, por exemplo, dos diversos rituais de passagem já conhecidos nas diferentes sociedades, como é, também, o caso das transformações íntimas/subjetivas do indivíduo que produz ou passa pelo ritual, como no caso, por exemplo, de sujeitos que experimentam o uso ritual do ayahuasca ${ }^{l}$.

Há, ainda, outro elemento importante na constituição do ritual: o local/espaço de realização do ritual. Mauss e Hubert (2005), afirmam que um ritual não pode ocorrer em qualquer lugar, nem de qualquer jeito, sob pena de perder seu efeito. O local deve ser destinado/consagrado ao rito.

Por fim, talvez o mais importante elemento do ritual para Mauss e Hubert (2005), seja o seu caráter coletivo. Para os autores, um rito não pode ser composto apenas por um envolvimento emocional individual, pois ele é, antes de tudo, uma forma de viver (celebrar) que é coletiva e, portanto, pública. É este seu caráter coletivo que gera o efeito da tradição e do costume. Segundo Lévi-Strauss (2003), é da natureza da sociedade que ela se exprima simbolicamente em seus costumes. Para esse autor, as condutas individuais (de uma pessoa que não tem problemas de saúde mental), jamais serão simbólicas por elas mesmas. Elas são os elementos a partir dos quais um sistema simbólico, que só pode ser coletivo, se constrói. Por isso, os ritos (mágicos) são fatos de tradição. Na medida em que têm uma eficácia particular e que fazem mais do que estabelecer relações entre os indivíduos, eles são mágicos.

\footnotetext{
${ }^{1}$ Erva usada em cerimonias religiosas, como, por exemplo, no Santo Daime.

${ }^{2}$ Para uma discussão sobre os conceitos de lazer de autores clássicos e contemporâneos, ver a obra
} 
Tal noção de ritual tem sido fundamental, no âmbito dos estudos antropológicos, na análise e compreensão da natureza simbólica do comportamento humano, nas diversas esferas da vida cotidiana. Longe de estarem vinculados apenas à dimensão do religioso, os rituais configuram expressões humanas distintas. Muito relacionado aos estudos sobre corporeidade, o rito no âmbito das práticas corporais e esportivas revela aspectos significativos dos indivíduos e grupos sociais. Alguns estudos já associaram as atividades esportivas aos estudos de Marcel Mauss, sobre ritual e magia. A maioria deles, no entanto, o fez a partir da noção de "sacrifício" imprimida no treinamento. Alguns exemplos são os estudos de Gonçalves e Vaz (2012), sobre a educação do corpo, da dor e do sacrifício em competidores de atletismo e o trabalho de Cavalcanti e Porpino (2015) que analisa o sofrimento e a dor como constituintes da beleza esportiva. A ideia de sacrifício, aparece como inerente a qualquer prática esportiva que tenha como finalidade a profissionalização e a competição. Pouco se tem produzido, no entanto, sobre os "rituais" corporais de praticantes amadores, que não têm como fim último a competição, mas que transformam seu envolvimento com uma determinada modalidade num verdadeiro rito, no qual está presente o sacrifício, mas também os outros elementos anteriormente citados, inerentes aos rituais mágicos. É o caso de milhares de corredores de rua, que mesmo não visando serem atletas profissionais, estabelecem uma rotina quase ritual de sua prática.

A corrida vem sendo largamente estudada, nos últimos anos sob diferentes aspectos. Encontramos pesquisas que analisam a corrida do ponto de vista de sua estrutura organizacional (ROJO et al., 2017a), bem como outros aspectos que dizem respeito ao universo das corridas de rua, suas instituições, seus agentes e sua atuação no mercado (ROJO et al. 2017b). Encontramos, ainda, pesquisas sobre a história da corrida 
de rua no Brasil (DIAS, 2017) e outras que focam especificamente os aspectos motivacionais da corrida de rua (BALBINOTTI et al., 2015; GRATÃO e ROCHA, 2016). Podemos citar, ainda, aquelas que analisam a corrida a partir da área biológica e biomédica, como exemplo, Purim et al. (2014), que aborda o índice de lesões entre os corredores. Há também pesquisas como de Oliveira (2016) que é de cunho etnográfico e parte da categoria de envelhecimento para investigar um grupo de corredores.

Se várias são as maneiras de abordar o fenômeno da corrida de rua, o que buscamos fazer aqui, neste artigo, foi olhar além destes aspectos estruturais, biomédicos ou motivacionais, refletindo sobre o caráter ritualístico presente no cotidiano dos corredores amadores, que ainda é pouco explorado. A corrida de rua se configura como uma prática esportiva, antes de tudo, social. Por isso nos debruçaremos em compreendêla a partir da noção de ritual de Mauss (2003), e também a partir de observações sobre as particularidades expressas por quem a pratica no contexto do lazer. O treinamento, assim como outros ritos, é um conjunto de atos formalizados que têm uma ordem característica que não pode ser quebrada, sob pena do objetivo não ser alcançado. Além do ritual de treinamento, há, ainda, a celebração que marca o ritual propriamente dito. Em rituais religiosos, por exemplo, a celebração pode ser uma festa destinada a uma divindade, mas no caso dos corredores de rua, a celebração é a prova coletiva (a corrida de rua).

Assim, consideramos que o esporte pode ser estudado em diferentes âmbitos, como, por exemplo, no profissional, no escolar e no do lazer. Com isso, não estamos dizendo que o esporte é necessariamente ou, a priori, uma prática do contexto do lazer, mas que essa é uma possibilidade de estudo e investigação. As discussões do lazer e estudos específicos sobre o lúdico, por exemplo, podem ser úteis, já que o foco será o 
corredor comum e não o atleta profissional. Para o corredor comum, que trabalha durante a semana, participar de atividades aos domingos pela manhã, por exemplo, é, em geral, uma atividade do seu tempo disponível, mais propício para a realização de práticas escolhidas para a realização no âmbito do lazer. Assim, interessa-nos, neste texto, analisar os elementos que envolvem o processo ritual dos corredores comuns, em uma prova de meia maratona. Ou, poderíamos dizer que, dentro das categorias sociológicas que caracterizam o lazer como tempo e atitude ${ }^{2}$, nosso olhar seria para os elementos culturais, em específico, o ritual, como elemento que constitui a corrida de rua. Mesmo entendendo que o próprio processo de treinamento é, por si só, ritualístico, focaremos neste artigo, o ritual de celebração e os elementos que o compõem. Neste caso, o ritual de celebração foi a Meia Maratona Pague Menos, realizada na cidade de Campinas/SP, no dia 11 de junho de 2017.

Partindo desta visão, de corrida como ritual, tomando como experiência empírica a Meia Maratona Pague Menos, neste artigo, vamos analisar os significados e valores presentes nas ações de alguns corredores comuns que participaram desta prova. Para isso, realizamos o esforço intelectual de aproximar alguns aspectos da teoria geral da magia de Mauss (2003) as referências clássicas do campo do lazer e da ludicidade. A intenção foi narrar algumas "cenas" observadas ao longo da corrida e interpretá-las à luz das noções de ritual e de seus elementos constitutivos.

Portanto, o problema investigado diz respeito às corridas de rua e os rituais demonstram a riqueza das formas de modus operandi dos vários participantes e grupos, que com objetivos distintos participam de provas de rua como, por exemplo, a meia maratona. Nosso pressuposto/hipótese é que o ritual é um elemento chave para analisar

\footnotetext{
${ }^{2}$ Para uma discussão sobre os conceitos de lazer de autores clássicos e contemporâneos, ver a obra SILVA e HASSE (2013).
} 
uma prova de meia maratona no âmbito do lazer, devido ao fato de gerar nos sujeitos transformações, ter carácter coletivo, ter eficácia simbólica e pelo local se constituir em um percurso da cidade. Agrega-se a essas características fatores constitutivos de uma atividade realizada no contexto do lazer a predominância do lúdico, a sociabilidade e, inclusive, valores que são próprios de quem disputa uma prova como atleta profissional, como a competição, já que no contexto em que se vive esse é um valor predominante nas sociedades capitalistas e certamente se expressa também entre os corredores comuns. Esse conjunto de características contribui para alimentar nos sujeitos a adesão à corrida e às provas de rua como a meia maratona, superando dificuldades como o cansaço e a dor. Assim, os objetivos da investigação são identificar e analisar os significados e aspectos ritualísticos produzidos pelos corredores durante a participação em uma prova de meia maratona.

\section{Métodos}

Este trabalho é de natureza qualitativa, já que, como assegura Minayo (1994), esse tipo de pesquisa trabalha com o universo de significados, motivos, aspirações, crenças, valores e atitudes dos diversos sujeitos. A revisão de literatura ocorreu mediante seleção de textos relacionados aos temas lazer e cultura, a partir de um referencial sociocultural. O debate, rigorosamente produzido durante as discussões do grupo de estudo, pautou-se em interesses relacionados às práticas corporais no âmbito do lazer e, especificamente, às corridas de rua. Ao nos depararmos com as estruturas ritualísticas desta atividade fomos conduzidos a leituras mais específicas sobre o conceito de rito e sua presença nas atividades esportivas e do contexto do lazer. Neste sentido, nos baseamos, principalmente, nos escritos de Marcel Mauss (2003) sobre a 
teoria geral da magia, bem como nas referências de autores que estudaram os aspectos lúdicos do ser humano como Roger Caillois (1990) e Johan Huizinga (2001). Também consideramos outros estudos do âmbito do lazer, clássicos e contemporâneos que nos ajudaram nas análises como Elias e Dunning (1992) e Marcellino (2003). Esse conjunto de autores forneceram o suporte para o aprofundamento nas análises e discussões, sobretudo com relação às manifestações de dois dos corredores analisados, que foram mais representativos pelas suas manifestações durante o percurso da prova.

A segunda fase da investigação, a pesquisa de campo ${ }^{3}$, foi realizada na prova de corrida de rua Meia Maratona Pague Menos da cidade de Campinas/SP, no dia 11 de junho de 2017. Uma das autoras da pesquisa participou da corrida e durante todo o percurso utilizou a técnica de observação participante. Foram observados aspectos como: os sujeitos participantes da prova, suas roupas, o que conversavam e fatos ocorridos durante o percurso da corrida. Durante a corrida a pesquisadora esteve atenta as ações dos corredores, sem, no entanto, qualquer tipo de contato eles. Imediatamente após o término da prova a pesquisadora/corredora registrou suas observações e interpretações iniciais, bem como verificou algumas informações no site ${ }^{4}$ da empresa que organizou a corrida e das empresas que fotografaram o evento.

Ao contrário de uma pesquisa mais "sociológica", que tende a utilizar amostras mais extensas e lidar com categorias apriorísticas, um olhar mais antropológico nos permite produzir reflexões a partir de um contexto ou caso mais específico. Em "O saber local”, Geertz (1997) fala sobre a possibilidade de compreender mais coisas sobre um determinado grupo analisando contextos específicos vivenciados pelo grupo. Neste

\footnotetext{
${ }^{3}$ Para esta investigação não foi necessário ter aprovação do Comitê de Ética em Pesquisa pelo fato de não termos usados recursos como entrevistas, questionários, histórias de vida etc. recursos que requerem aprovação dos sujeitos pela necessidade de interação com eles.

${ }^{4}$ Site http://noblu.com.br/eventos-proximos/41/7-meia-maratona-pague-menos-campinas/
} 
sentido, o autor defende que, similar a sua famosa análise sobre a "briga de galos balinesa" (GEERTZ, 1989), é possível compreender os comportamentos sociais de um grupo observando, por exemplo, um ritual. Neste sentido, o fato de termos utilizado como dado empírico uma única prova de rua, não restringe nosso esforço intelectual de interpretação que buscou realizar uma construção teórica de modo a “(...) não codificar regularidades abstratas, mas tornar possíveis descrições minuciosas; não generalizar através dos casos, mas generalizar dentro deles" (GEERTZ, 1989, p.36).

Como afirma Fonseca (1999), num estudo com viés etnográfico, um caso particular pode se tornar representativo em esferas mais gerais, a posteriori. Segundo a autora, ao contrário das análises usuais, onde o particular é usado para ilustrar ou testar uma afirmação geral, nas pesquisas mais antropológicas é só depois que se analisa o campo que se pode compreender sua representatividade. Ou seja, a contribuição desse estudo se dá a partir da identificação de elementos ritualísticos que podem ser generalizados, sem, necessariamente, precisarem ser. Neste sentido, são bem-vindos estudos futuros que venham repetir a experiência aqui realizada, em outras localidades, com o objetivo de se fazer comparações acerca do conjunto de observações realizadas.

Para realizar as interpretações fazemos o mesmo tipo de esforço intelectual que os antropólogos fazem em suas investigações, tendo como inspiração a descrição densa de Geertz (1989). Em um segundo momento, compartilhou-se as anotações com o grupo de pesquisadores que, por sua vez, debateu os dados à luz do referencial teórico e complementou as análises. A elaboração da análise foi organizada a partir da descrição de fatos ou "cenas" observadas pela pesquisadora corredora, durante a prova de meia maratona. Nestas "cenas" é possível identificar alguns elementos rituais. 


\section{Contextualização do Campo Investigado}

A corrida de rua é uma prática que possui diversos significados e valores para seus praticantes. De acordo com Masson (2016), tendo como referência os estudos de Dallari (2009), a corrida de rua surgiu no século XVII, na Grã-Bretanha. A classe operária teve maior prevalência, nessa época, na participação das corridas, fato este devido aos patrocínios das grandes empresas. A primeira corrida com média de tempo e classificação aconteceu em 1937, teve uma distância de 84 km e ocorreu em Londres.

A corrida foi popularizada na Inglaterra no século XVIII, posteriormente se expandiu pela Europa e Estados Unidos no século XIX. Ganhou destaque mundial quando foi percorrida e oficializada a distância de 42.195 metros na Maratona Olímpica de Londres, no ano de 1948. No Brasil, no século XX, aconteceu a maratona de São Silvestre, que ocorreu nas ruas da cidade de São Paulo e teve como organizador o Jornalista Casper Líbero, que promoveu o evento baseado em uma corrida noturna que presenciou na França. Com base em Dallari (2009), entre os anos de 1970 e 1980, no Brasil, a corrida de rua era vista como uma prática militarista, destinada a corredores de alto rendimento. Somente a partir de 1980 ela passou a ser mais praticada por corredores amadores. Desde então, provas como a Meia Maratona Pague Menos têm sido cada vez mais frequentes, bem como o número de corredores amadores têm aumentado substancialmente nos últimos anos.

A escolha desta prova para a realização das observações foi por conveniência, uma vez que no período da prova já havíamos amadurecido as pesquisas e reflexões sobre a corrida de rua e sua estrutura ritualística. A Meia Maratona Pague Menos é uma prova relativamente tradicional na cidade de Campinas, já que esta, realizada no ano de 2017 foi sua $7^{\circ}$ edição. A prova possui três diferentes percursos em termos de distância 
e os participantes podem optar por correr $6 \mathrm{~km}, 10 \mathrm{~km}$ ou $21 \mathrm{~km}$. Até a sua $5^{\circ}$ edição, em 2015, a prova foi patrocinada pela empresa Amil e a partir de 2016 passou a ter o patrocínio do supermercado Pague Menos. Vale dizer que essa foi a primeira prova na cidade de Campinas a ter a distância de uma meia maratona $(21 \mathrm{~km})$. Diversas provas com distâncias até $10 \mathrm{~km}$ são realizadas na cidade. Desde 2015 a cidade de Campinas comemora seu aniversário, no mês de julho, com a prova "Maratona de Campinas" com distâncias de $7 \mathrm{~km}, 14 \mathrm{~km}, 21 \mathrm{~km}$ e $42 \mathrm{~km}$. Ou seja, desde 2015 a cidade conta com duas provas de meia maratona por ano.

A Meia Maratona Pague Menos de 2017 teve 1734 participantes divididos da seguinte maneira: prova de 6km (107 homens, 124 mulheres); prova de 10km (252 homens, 216 mulheres); prova de $21 \mathrm{~km}$ (821 homens, 214 mulheres). A largada foi às 7 horas, saindo da Av. Francisco Glicério, Centro de Campinas/SP e a chegada foi no mesmo local. O tempo máximo de duração da prova foi de 3 horas. Os inscritos necessariamente tinham que ter idade mínima de 18 anos. A prova também incluía pessoas na categoria de deficientes.

A pesquisadora corredora está na faixa etária entre 40-44 anos, pratica corrida há cerca de oito anos e desde 2016 começou a participar de provas de meia maratona. Até o momento ela havia corrido duas dessas provas, ambas na cidade de Campinas. Para a pesquisadora a corrida é uma atividade praticada diariamente e se configura como uma atividade realizada no contexto do lazer. Ela também participa, frequentemente, de provas de corrida de rua com diferentes distâncias. 


\section{Resultados/Discussão: Cenas Observadas Durante a Corrida}

\section{Antes e Durante a Largada: A Eficácia Simbólica na Preparação para o Ritual}

Apesar do frio, já que o termômetro marcava cerca de $12^{\circ} \mathrm{C}$, o ambiente era festivo. As vozes masculinas se sobressaíam, uma vez que era possível perceber que a grande maioria dos corredores eram homens. As pessoas, em geral, tinham roupas próprias para corrida (camisetas, calças, bermudas ou shorts e tênis). Era possível identificar um "mar de gente" com a camiseta que vem no kit que cada corredor recebe pela inscrição na prova. Alguns tinham camisetas diferentes, de patrocinadores - esses, em geral, são corredores profissionais ou pessoas que representam empresas ou algum tipo de instituição. As pessoas que fazem parte de grupos de corrida também vão com camisetas personalizadas, diferentes da camiseta oficial da prova. Assim, pelas vestimentas, é possível classificar, de modo geral, três tipos de grupos: os que correm como profissão ou tendo algum tipo de vínculo com empresas, os que tem vínculo com grupos específicos de corrida e os sujeitos que não fazem parte de nenhum dos dois grupos anteriores. Antes da largada as pessoas se alongavam, algumas corriam em forma de trote, como parte do aquecimento, outras se benziam e oravam, outras, ainda, tiravam fotos junto a seus grupos de corrida, como uma forma de registro de participação na mesma. Em certo momento, o interlocutor fez a chamada de todos para a largada. A largada da prova foi um tanto confusa para aqueles que ficaram mais para o final do bloco de pessoas como foi o caso da pesquisadora corredora. Foi necessário aguardar alguns segundos até que os corredores que estão mais à frente atravessem a linha da largada.

Como em todo ritual, há uma hierarquia entre os indivíduos que dele participam. Criando certa analogia com aquilo que Mauss (2003) aponta, podemos considerar como 
mágicos aqueles que possuem certa hierarquia na teia de relacionamentos dos corredores. Ou seja, dentre tantos participantes, alguns possuem maior representatividade e se tornam detentores de certo poder mágico que é respeitado pelos demais. É o caso, por exemplo, de um corredor mais experiente que partilha informações e técnicas importantes que serão seguidas pelos demais corredores. Essa transmissão de experiência de uma pessoa para outra garante a eficácia do "mágico" e a tradição inerente ao ritual. Os conhecimentos transmitidos podem ser as "técnicas" usadas no aquecimento e no decorrer da corrida, pelos seus participantes. O mágico nem sempre é outro corredor, pois ele pode ter uma função profissional, como é o caso do instrutor de corrida ou de um ex-corredor que transmite sua técnica.

Os preparativos para a largada também são elementos que caracterizam um ritual. Eles estão presentes nos alongamentos e aquecimentos, mas também em ações como rezar e benzer-se. Neste caso, os efeitos do aquecimento e do alongamento são geralmente avaliados do ponto de vista biológico. Algumas pessoas, inclusive, preferem se alongar somente após a corrida, justificando que na fase de preparação o aquecimento que consiste em alguns movimentos de deslocamento é mais eficiente do que o alongamento em si. É importante notar que nessa justificativa considera-se, principalmente, os efeitos fisiológicos preparatórios para a corrida, ou, o que Mauss (2003) chamaria de efeito mecânico. As ações de rezar e benzer-se, no entanto, são elementos distintos, já que, com base em Mauss (2003), seus efeitos não são necessariamente fisiológicos, mas sobretudo, simbólicos. Se o alongamento e o aquecimento estão mais relacionados à eficiência, o benzer-se e o orar estão relacionados ao que o autor denomina de "eficácia simbólica". Esses são exemplos e justificativas dadas para explicar o comportamento dos corredores no momento da 
largada de uma prova de rua, no entanto, há que se considerar que, segundo o próprio Mauss (2003), qualquer ação humana é simultaneamente biológica, simbólica (cultural), psicológica e social. O que quisemos, no entanto, foi demonstrar que benzer-se pode ser um ato considerado desnecessário como parte da preparação para a corrida, se avaliado exclusivamente a partir do ponto de vista biológico ou fisiológico, no entanto, é imprescindível do ponto de vista simbólico e cultural para alguns corredores.

\section{Sobre os Homens que Tiram SarrodDe di Mesmos e os Aplausos aos Primeiros}

\section{(Homens) da Corrida}

Após cerca de dois quilômetros de corrida, foi possível notar a formação de blocos de pessoas, que corriam mais agrupadas, diferentemente da largada em que a multidão reunida se espalhou pela rua, sendo possível notar cada pessoa correndo em um ritmo diferente. A pesquisadora corredora estava próxima de alguns corredores, sendo que um deles falava com o outro tirando sarro de si mesmo, meio que cantarolando "eu bebo pra correr, eu corro pra beber, sabe qual é minha religião? É evangelicóolatra".

Um pouco depois disso, o que era apenas a parte inicial da corrida para os corredores comuns ${ }^{5}$, para os atletas profissionais já era a etapa final. Em determinado trecho da corrida era possível ver alguns atletas profissionais já se encaminhando para o final da prova (provavelmente atletas que estavam correndo $6 \mathrm{~km}$ ou $10 \mathrm{~km}$ e não os $21 \mathrm{~km})$. Nesse momento, alguns corredores comuns aplaudiram os profissionais. Há que se dizer que esses primeiros corredores eram homens. Quando passou a primeira mulher da prova que estava em primeiro lugar ninguém se manifestou, nem homens, nem

\footnotetext{
${ }^{5}$ Esta denominação se refere a todos os corredores que estavam participando da prova como uma atividade não profissional ou do contexto do lazer.
} 
mulheres, dentre os corredores comuns. Essa era a demonstração de que as mulheres estavam em um território predominantemente masculino. Embora esta constatação fosse visualmente notável, com os aplausos isso se tornou óbvio. Também é possível perceber, pela manifestação, que os corredores comuns reconheciam o valor dos corredores profissionais, pelo desempenho que não estava ao alcance desses primeiros, sobretudo aos homens comuns.

O espaço do ritual, como afirmava Mauss (2003), é destinado às pessoas aptas a ele. Em alguns trechos de sua análise, o autor comenta sobre o papel dos homens nos atos rituais e o fato de que a mulher é vista como coadjuvante. Se as sociedades analisadas por Mauss (2003) há cerca de 100 anos operavam com a lógica patriarcal e machista, o esporte (e a corrida neste caso) tem se tornado, aos poucos, um espaço mais democrático. É fato, no entanto, que homens e mulheres ainda não atingiram um patamar de igualdade no que diz respeito ao número de participantes de cada gênero, nas modalidades esportivas. Basta olhar para o número de inscritos na prova de $21 \mathrm{~km}$. Como já mencionamos anteriormente, segundo os dados do site da corrida, foram 821 homens inscritos e, apenas, 214 mulheres. Ainda que o número de mulheres inscritas na prova de $6 \mathrm{Km}$ tenha sido superior ao número de homens, a única diferença extremamente significativa entre os gêneros se deu na prova de maior distância $(21 \mathrm{~km})$. Os homens estavam presentes em maior número na prova dos 10Km também. Talvez, por isso, o reconhecimento só foi dedicado aos primeiros homens que completaram a prova, mas não a mulher, que seguiu sem aplausos.

Essa manifestação dos corredores "comuns", aplaudindo os primeiros, sinaliza o reconhecimento do "poder mágico" que os corredores profissionais possuem. São mágicos porque são eficientes e eficazes. Tal eficácia se confirma não somente pelos 
aplausos aos atletas, mas também pelo fato de que outros homens, menos "mágicos", tiraram sarro de si mesmos, pois tinham consciência de sua má performance.

Ao brincar que sua religião era "evangelicóolatra", o corredor amador tirava sarro dos evangélicos, mas, acima de tudo, tirava sarro de si mesmo. É interessante notar que esse tipo de manifestação expressa pelo corredor é uma forma de demonstrar consciência de que não é um atleta profissional e de se desculpar antecipadamente pela má performance. A brincadeira era, portanto, uma forma de justificativa antecipada por não se sair bem na prova.

Fica claro, nesta brincadeira, o elemento lúdico do ritual, o qual enaltece a aderência do participante amador, que trata o evento muito mais como prática de lazer do que como competição. $\mathrm{O}$ fato, no entanto, de sua adesão se dar pelo âmbito do lazer, não significa, em si, que a corrida não é algo sério para este participante. Sabemos, que o fato de uma prática ser realizada no contexto do lazer não inibe a seriedade com que os sujeitos nela se envolvem. O lúdico, aqui, aparece como um elemento na participação do corredor amador, mas o que lhe distingue, de fato, do profissional são os motivos de adesão ao ritual. Ainda que uma pessoa corra por profissionalismo e outra por diversão, ambos participam juntos da celebração final (elemento constituinte de todo ritual) que é a corrida.

As amigas

Chegávamos mais ou menos na metade da prova de meia maratona, já havia um pouco mais de uma hora de corrida. Como a meia maratona é uma prova longa, que pode ter a duração máxima de até três horas, em determinado momento a prova passa a ser um tanto monótona. No entanto, algumas pessoas encontram formas de suavizar essa monotonia. Algumas amigas que estavam próximas da pesquisadora corredora, por 
exemplo, conversavam sobre a inscrição em outra prova de corrida da qual queriam participar. O interessante é que elas estavam em três e iam todas em um mesmo ritmo, dando a perceber que estavam gostando de conversar um pouco. Depois de um tempo uma delas acelerou o passo e ficou relativamente distante das outras duas. Essa atitude das amigas nos revela, novamente, o aspecto lúdico presente nas corridas, pois, para elas, não havia a demonstração de preocupação com o tempo ou do maior gasto de energia por estarem conversando, o que parecia valer para elas, naquele momento mais monótono da corrida, era a companhia uma da outra e o compartilhar de informações sobre provas de corrida. A interação entre elas era evidente, revelada pelo laço de amizade.

Esta relação entre "as amigas" confirma que a corrida é, para alguns sujeitos, um elemento do contexto do lazer, permeado pela não obrigatoriedade. Elas correm e conversam ao mesmo tempo, não demonstrando grande esforço e nem muita preocupação com o tempo. Com base em Marcellino (2003), podemos identificar a interrelação entre a corrida e a sociabilidade e que a corrida é uma atividade de educação pelo lazer, pelas trocas de informações e valores entre as amigas aqui no caso, acerca da corrida. Um tipo de educação não formal, transmitida a partir da cultura e que se produz no coletivo.

Como mencionamos acima, a celebração do ritual, que no caso deste texto é uma prova de corrida, evidencia o caráter de coletividade, descrito por Mauss (2003). Se ao longo do ano os corredores treinam a sós, ou em grupos, é nos momentos de participação em provas de corrida (celebração coletiva) que eles se reúnem para consagrar toda a preparação que desenvolveram nos treinos, ainda que esses não tenham sido propriamente no sentido do treinamento como para um atleta profissional. $\mathrm{O}$ 
elemento de coletividade dá sentido/significado ao ritual, já que, lembrando LéviStrauss (2003), um ritual jamais se produz a partir de experiências individuais.

\section{A Val e o Super-Homem}

Por volta dos $14 \mathrm{~km}$ percorridos foi possível se aproximar de dois corredores: uma mulher de meia idade que usava uma camiseta personalizada de grupo de corrida, escrito "Val" na parte de cima das costas e um homem também de meia idade, talvez um pouco mais novo do que a mulher. Ele estava vestido com uma fantasia de superhomem. Tinha um lenço cobrindo a cabeça e usava uma roupa azul e vermelha, composta por uma capa, igual a do super-homem dos filmes. É comum em provas de corrida a presença de algumas pessoas fantasiadas. Talvez isso seja mais frequente e com número maior de pessoas em provas transmitidas pela televisão, como a Corrida São Silvestre, por exemplo, que ocorre todo dia 31 de dezembro em São Paulo e é transmitida pela Rede Globo. Em Campinas, há uma prova que costuma ter um número maior de pessoas fantasiadas, a Corrida Integração, com cobertura jornalística da EPTV. No entanto, é menor o número de pessoas fantasiadas em provas como essas, que são consideradas relativamente pequenas e sequer são televisionadas. A partir deste momento da corrida foi possível perceber que estes dois participantes se manteriam próximos à pesquisadora corredora por alguns quilômetros de prova. Já dava para perceber, devido ao número reduzido de pessoas nas proximidades, que esta era a parte do terço final de corredores da prova de meia maratona. Correndo lado a lado, foi possível identificar algumas características da Val e do "super-homem". A Val parecia estar mais concentrada na corrida, tentando manter um ritmo constante, embora demonstrando certo cansaço, que era expresso em seu rosto. $\mathrm{O}$ "super-homem" tinha um 
jeito mais extrovertido. Ele ia falando durante a corrida, com comentários sobre a dificuldade da prova, as subidas que eram sempre mais difíceis, entre outros comentários. Ele, de repente, "puxou conversa" com a Val. Ela parecia inicialmente dar breves respostas, não querendo muita conversa, mas demonstrando simpatia, o que pode ser justificado pelo cansaço. Foi possível notar que em alguns momentos a Val avançava e o "super-homem" tentava acompanhá-la. Faltando cerca de um pouco mais de $2 \mathrm{~km}$ para o término da prova, Val e o "super-homem" pareciam mais próximos, pois conversavam sobre relacionamentos amorosos. A Val perguntou ao "super-homem" qual era seu estado civil. Ele respondeu que já tinha sido casado e deu a entender que agora tinha uma namorada, mas ela não era atleta, ainda. Seguiram assim, ele demonstrando mais extroversão, acenando para as pessoas na rua e brincando com os próprios organizadores da prova que estavam oferecendo água no último ponto de hidratação da corrida. Ele recusou a água e foi logo dizendo "sou o super-homem, não preciso de água". Os organizadores da prova sorriram, entrando no espírito da brincadeira. Após esse ponto da prova viria uma subida, com maior ponto de elevação, o viaduto conhecido como Laurão, nas proximidades do centro de Campinas. Chegando ao viaduto, Val e o "super-homem" que estavam mais à frente da pesquisadora corredora, pararam de correr e passaram a caminhar, nesse momento a pesquisadora também começou a caminhar. De certo modo, os dois passaram a ser uma referência para a pesquisadora, já que eles eram visualmente mais acessíveis, dentre os corredores que ainda restavam na prova à frente da pesquisadora. Como a subida era muito acentuada, Val e o "super-homem", junto de outra corredora, se organizaram para tirar algumas fotos e descansar. Nesse trajeto, o "super-homem" perguntou para a Val se ela tinha uns 42 anos. Val respondeu que tinha um pouco mais e ele demonstrou um pouco 
de surpresa, talvez por ela ser mais velha que ele e, mesmo assim, não demonstrar cansaço excessivo na prova, como ele talvez estivesse sentindo. Em alguns momentos, a Val tinha ficado um pouco à frente dele e ele reagia de modo a tentar alcançá-la.

O uso da fantasia tem um significado público, pois não há como não notar a presença de um "super-homem" participando da corrida. Todas as pessoas que estavam acompanhando a prova, pessoas da própria organização e até os que estavam passando pela área da corrida notavam a presença daquele "super-herói". A fantasia provocava um sentido de deboche de si mesmo, já que se tratava de um corredor que estava entre os últimos da prova. Ou seja, a figura de um personagem que é superior aos humanos, por suas habilidades, poderes e capacidades era algo totalmente destoante da imagem daquele corredor que estava entre os últimos a completarem a prova.

Ao contrário, Val não demonstrava qualquer tipo de interesse que não fosse a própria conclusão da prova, isso devido a sua atitude de esforço, ao tentar manter o mesmo ritmo de passadas, em silêncio, demonstrando poupar energia. Como ela estava identificada com um grupo de corrida, isso era a revelação de seu "roteiro" ou papel na corrida. Essa atitude da Val mostra que as atividades do contexto do lazer, como as provas de corrida de rua, não são vivenciadas da mesma forma por todos. Ao contrário disso, podemos pensar que os corredores vivenciam a corrida com diferentes propósitos, atribuindo a ela diferentes significados, ainda que estejam unidos pelo fato da atividade ocorrer no contexto do lazer. Enfim, a aproximação do "super-homem" com a Val denota um tipo de interação sem que tenham tido necessariamente vínculo anterior como é o caso das amigas narradas anteriormente, caracterizando outra forma de interação durante o ritual. 
De acordo com a teoria da magia de Mauss (2003), Val cumpriu o ritual de preparação e experimentou o ritual de celebração (idem). Sua preparação como corredora, desenvolvendo condições físicas que fossem suficientes para ter êxito na prova, sem ocasionar prejuízos pessoais ou físicos para si mesma foi parte importante do ritual e muito provavelmente foi guiada pela motivação de fazer parte de um grupo de corrida, demonstrando, assim, a eficácia do coletivo.

Mais uma vez é possível fazer menção ao caráter lúdico presente nos rituais. É possível perceber nos escritos de Mauss (2003), e de Mauss e Hubert (2005) a dimensão da ludicidade em certos momentos do rito. É no trabalho de Huizinga (2001), no entanto, que fica claro o elemento lúdico do ritual, bem como o caráter sério do lúdico.

\section{O Fim do Ritual ou Sobre a Glória e o Sacrifício de um Corredor}

Esse era um momento importante da prova, no qual os corredores devem conter energias, pois faltava ainda um pouco mais de $1 \mathrm{~km}$ para o término da prova e o desgaste corporal já era grande. Após andar um pouco era necessário recuperar o ritmo e concluir a prova. Nessa altura, o corredor tem um impulso para testar seus próprios limites corporais. Entra-se na fase do sacrifício da corrida.

Passada a subida do viaduto Laurão, o percurso continuava por algumas ruas mais curtas, rumo à Av. Francisco Glicério, que fica no centro da cidade de Campinas, mesmo local onde foi o ponto de largada da prova. Nesse momento, a pesquisadora corredora acelerou, e pôde ouvir do "super-homem": "a glória na Glicério". Esta expressão demonstrava certo alívio por estar chegando ao término da prova. A pesquisadora corredora manteve um ritmo mais acelerado e ultrapassou a Val e o "super-homem" e seguiu na reta da Av. Francisco Glicério. Havia poucas pessoas aos 
arredores do final da prova. À frente da pesquisadora agora estava um senhor de bastante idade, indo em ritmo constante, mas mais lento do que o dela. Assim, a pesquisadora viu que era possível ultrapassá-lo e o fez. Val e o "super-homem" já tinham ficado para trás. Faltava cerca de 30 metros para a chegada, o relógio já apontava em torno de 2 horas e 30 minutos de tempo desde a largada da prova. De repente, "o super-homem" passa à frente da pesquisadora corredora. Foi somente nesse momento que a pesquisadora se deu conta que o "super-homem" poderia estar em uma disputa não só com ela, mas também com a Val, com quem vinha por alguns quilômetros em ritmo próximo, de modo a trocarem informações, inclusive de assuntos particulares. Pode ter ocorrido o fato de ele ter feito um esforço maior para tentar passar a pesquisadora já que ela, diferente da Val não tinha demonstrado simpatia ou tido algum tipo de interação mais direta com ele. $\mathrm{O}$ fato é que ele passou e foi possível notar que estava mancando, quase sem conseguir pisar no chão. Ao cruzar a linha de chegada, foi imediatamente ao chão, segurando uma das pernas, provavelmente devido às câimbras. As pessoas da equipe organizadora prontamente foram socorrê-lo. A pesquisadora corredora, após a linha de chegada, se dirigiu à fila para receber sua medalha junto com os outros participantes da prova.

O fato ocorrido pode ser justificado pela questão de a reta final ser o momento em que, em geral, os corredores têm vontade de acelerar, pois é o último esforço após a chegada, é o sacrifício final. No entanto, no caso do "super-homem" o seu esforço parece ter ido além de seus limites físicos, poderia ter ali uma questão de disputa, de competição, mas também de honra no sentido de demonstrar sua masculinidade, já que seria um tanto vergonhoso ele publicamente perder a prova para duas mulheres (Val e a pesquisadora) e um senhor bem mais velho, que era um público minoria na prova. 
Assim, entre o espírito da competição e a honra em defesa da masculinidade foi o desenrolar da glória e do sacrifício do "super-homem" ao final da corrida. Após a verificação dos resultados da corrida foi possível identificar que o "super-homem" não estava oficialmente inscrito na prova, o que ocorre com frequência em provas de rua. Talvez ele não fosse propriamente uma pessoa que tenha uma rotina de preparação para provas desse tipo.

A conclusão que podemos chegar é que as manifestações do "super-homem" é uma demonstração de sua masculinidade. Este é um tema que aparece aqui, mas que já tem sido foco de outros trabalhos publicados nos últimos 10 anos, tais como: Pinto e Almeida (2014), sobre as torcidas organizadas queers no futebol; Sancho et al. (2010), sobre a aprendizagem da masculinidade de garotos jovens; Camargo (2014), sobre as masculinidades esportivas protagonizadas pelos atletas homossexuais masculinos em eventos como os "jogos gays"; além de ser um tema debatido em textos de autores da sociologia do esporte como Dunning e Maguire (1997), que discutem as relações entre os sexos no esporte. Esses últimos autores têm como base Brittan (1989, p.77) que afirma “(...) os homens têm pouquíssimas ocasiões de ser heróis, a não ser como passatempo ou nos esportes”. Essa é uma explicação para o caso em análise do corredor “super-homem”. Sua manifestação mostra-se algo como exemplo da construção social da masculinidade, que popularmente dizendo, está associado ao homem-herói, ao caçador, ao competidor, ao conquistador. No entanto, as oportunidades de manifestação desse imaginário na sociedade atual são restritas, já que as atividades corriqueiras dos homens contemporâneos não é mais do caçador ou não se restringe a figura do atleta. Assim, o "homem comum" talvez tenha que encontrar outras formas de manifestação ou 
afirmação desse imaginário, sendo o esporte uma oportunidade para isso, ou um dos principais espaços para essa manifestação, como se revelou nesse trabalho.

As cenas narradas vão também ao encontro das ideias de Elias e Dunning (1992) sobre a competitividade e seriedade no modo de envolvimento e orientação para os resultados, em todos os níveis do desporto, sendo assim, ainda que exista a classificação dos corredores dita "comum" denominada como participantes no contexto do lazer é possível que estes se incorporem de certa competitividade durante a prova, seja com relação a seus próprios limites, ou seja, com relação à defesa da honra (como citado nas observações).

Nota-se que tanto nos jogos como nos esportes é bem nítido o anseio pela vitória, para que de posse desta o jogador possa se vangloriar perante o seu oponente. Huizinga, (2001) afirma ser inato o desejo de ser o primeiro, de ser o melhor, o que continuará levando os grupos de poder a entrar em competição. Tanto Caillois (1990) como Huizinga (2001) destacam a importância da competição para o jogo/desporto, pois por meio do espírito competitivo o corredor buscará sua melhor performance e seu melhor resultado. Um bom resultado certamente trará benefício para si próprio (como elevação da autoestima) e também para o seu grupo de corrida (talvez seja um dos motivos da "Val" não ter conversado muito com o "super-homem" e centrado mais na prova). Esses autores consideram a competição como parte dos saberes prévios dos seres humanos, um elemento inato. No entanto, ao recorrermos a Mauss (2003), podemos complementar esse pressuposto, já que esses saberes prévios expostos em forma de crença e de rito são alimentados pelos significados (ou símbolos) que são produzidos publicamente. Esse é um elemento importante para que o rito e o ato mágico 
sejam eficazes e possam, inclusive, amenizar dificuldades que envolvem a dor e o sacrifício, como se pode observar na atuação do "super-homem".

O fato de alguns corredores demonstrarem forte espírito competitivo (seriedade), não significa como já mencionamos que o componente lúdico possa ser descartado. Ao contrário, a ludicidade é o elemento em destaque, principalmente quando se trata de amadores e participantes que se enquadram no contexto do lazer. Neste sentido Huizinga, (2001, p.38) destaca que "[...] o fato de a maior parte das competições dos gregos serem realizadas com uma seriedade mortal não é razão para separar o agón ${ }^{6}$ do jogo, ou para negar o caráter lúdico do primeiro" [...].

Em relação ao "super-homem" podemos analisar, ainda, de acordo com a afirmação de Huizinga, (2001, p. 40), quando este afirma que: [...] "Um dos frutos da vitória pode ser a honra [...]". Ainda que o "super-homem" não tenha chegado nem perto da vitória, já que foi um dos últimos, o sentimento de competitividade em detrimento da defesa de sua honra se aplica no sentido de não perder para duas mulheres eu um idoso. Foi notável o momento em que ele parecia se esforçar além dos seus limites físicos para realizar as ultrapassagens e cruzar a linha de chegada, caindo no chão por causa das dores. Percebe-se que apesar do "super-homem" sequer estar escrito na corrida, o sentimento de competitividade pode ter sido acionado por um tipo de sentimento machista. É comum, em casos como este, uma rivalidade de gênero, relacionada basicamente à força e a superioridade. Como aponta Caillois (1990), [...] "a rivalidade não se encontra codificada e pouco lugar ocupa nas instituições, e, quando isso se verifica, é frequentemente sob a forma de uma mera prova de força ou de um redobrar de prestígio" [...] (CAILLOIS, 1990, p. 150).

\footnotetext{
${ }^{6}$ Uma das características dos jogos que diz respeito ao fator competição, sendo Caillois (1990).
} 
A palavra competir sugere que se disputa algo com alguém que almeja a mesma coisa. A vitória, neste caso, é o objetivo maior de quem compete e sua conquista está completamente relacionada a honra. No caso da corrida, há outra coisa em jogo: a medalha recebida pela conclusão da prova, por exemplo. A medalha é a prova material de uma conquista e por isso possui imenso valor simbólico para o competidor, que certamente irá se lembrar de não somente de sua dedicação e preparação, mas também de todo seu esforço para conseguir completar a prova; essa é a sua vitória (transformação) pessoal e, neste caso, a colocação em termos de posição alcançada na prova torna-se secundária. Este êxito, $[. .$.$] "dá ao jogador uma satisfação que dura mais$ ou menos tempo, conforme o caso. O sentimento de prazer ou de satisfação aumenta com a presença de espectadores, embora esta não seja essencial para esse prazer” [...] (HUIZINGA, 2001 p. 39).

Talvez o maior fruto da vitória no caso das mulheres (Val e a pesquisadora) esteja centrado na superação de seus próprios limites - que são os principais adversários - tanto físicos como psíquicos. Isto possivelmente servirá como estímulo para que continuem não só com a prática da corrida, mas também com participações em outras provas mais longas, experimentando, dessa forma, os novos desafios e novos limites a serem superados.

Ao se fazer uma comparação dos resultados da presente investigação com trabalhos já publicados, podemos identificar que o sacrifício e a dor na situação do ritual são elementos presentes no caso de atletas profissionais, em treinamentos esportivos, e puderam ser aqui também observados. Assim como na pesquisa com os atletas de atletismo de Gonçalves e Vaz (2012, p.8), o sacrifício dos corredores da presente investigação é notável, assim como a dor, mais claramente demonstrada no caso do 
“super-homem”. De acordo com tais autores, ao mencionarem a dor psicológica no caso de atletas profissionais, afirmam que se trata de um "[...] dispositivo que dificulta ainda mais a relação entre competidor e competição, pois prejudica o desempenho, resultando em rendimento abaixo do esperado. A tensão gerada perante a competição traz consigo alterações subjetivas representadas, principalmente, pelo 'medo de perder'”. Assim, talvez a diferença a ser observada aqui nesta investigação é que o "super-homem" é um corredor comum ou corredor esporádico, participante da prova de corrida de rua, diferente do atleta profissional que tem uma rotina preparatória para a modalidade que irá competir. Ainda assim, foi possível identificar que a dor, o sacrifício e o ritual não são elementos exclusivos de quem treina e é atleta profissional, mas também se manifesta no caso do sujeito comum que participa de provas de esportes como no caso aqui observado, durante a realização de uma prova de meia maratona.

\section{Conclusões}

Com a análise de uma prova de meia maratona realizada na cidade de Campinas/SP a partir da noção de ritual de Mauss (2003) e dos estudos do lazer, foi possível compreender os significados atribuídos pelos próprios corredores aos aspectos ritualísticos presentes na prática da corrida. As análises, pautadas nas discussões baseadas na teoria da magia de Mauss (2003) e de estudos clássicos do lazer, predominantemente, revelaram relações análogas entre os elementos da corrida e os elementos constituintes do ritual: 1) a eficácia simbólica de uma reza ou do ato de benzer-se; 2) As possíveis transformações pessoais que cada um conquistou com a participação no ritual; 3) a corrida como espaço/tempo destinado a celebração coletiva de quem corre; 4) a ludicidade presente no ritual, mesmo este sendo competitivo; 5) as 
diferentes formas de interação social que só são possíveis num ritual coletivo, entre outras coisas.

O fato, por exemplo, da corredora Val revelar, por meio da sua camiseta, o pertencimento à um grupo de corrida nos remete a uma ideia do quanto "preparação e celebração" são elementos correlacionados no processo ritual. Há um aspecto fundamental no vínculo entre Val e seu grupo que está centrado na partilha dos resultados obtidos nas provas, incluindo os êxitos, fracassos, glória e sacrifício. O êxito se deve ao fato de Val ter completado a prova. Essa conquista está relacionada a superação dos limites e, consequentemente, a transformação pessoal pela qual Val passou com a experiência do ritual. O elemento de transformação é chave para analisar a participação individual de Val, mas também do coletivo. Segundo Huizinga (2001), trata-se de uma característica fundamental do jogo o momento em que o êxito obtido individualmente se transfere prontamente ao grupo.

Também foi possível observar que na corrida há grupos com interesses diversos e que o ato de correr, pelo menos para os sujeitos aqui analisados, estava muito mais relacionado ao componente lúdico do que propriamente competitivo. Isto se deve ao fato da participação ser espontânea e não uma obrigação.

Ao fazermos este esforço de aproximação com a teoria da magia de Mauss (2003), percebemos que todos os corredores estavam envolvidos e mobilizados pelo ritual da corrida, por seus significados produzidos e partilhados. Assim, esta aproximação que elaboramos - entre corrida de rua e ritual - pode ser considerada uma das possíveis leituras sobre o fenômeno. A compreensão da corrida de rua como uma ação composta por diversos elementos ritualísticos pode ser uma visão complementar na busca da compreensão de nosso objeto de análise, gerando novos elementos para 
estudos futuros, no sentido de se compreender a corrida de rua como um elemento da cultura, composto de crença, ação, dor, sacrifício, ludicidade e transformação.

\section{REFERÊNCIAS}

BALBINOTTI, Marcos Alencar Abaide; GONÇALVES, Gabriel Henrique Treter; KLERING, Roberto Tierling; WIETHAEUPER, Daniela; BALBINOTTI, Carlos Adelar Abaide. Perfis motivacionais de corredores de rua com diferentes tempos de prática. Revista Brasileira de Ciências do Esporte, v. 37, n. 1, 2015. p. 65-73.

BRITTAN, Arthur. Masculinity and Power. Oxford: Basil Blackwell, 1989.

CAMARGO, Wagner Xavier de. Considerações antropológicas sobre sexualidades e masculinidades no esporte. R@U, v.6, n.1, 2014. p. 41-62.

CAVALCANTI, Loreta Melo Bezerra ; PORPINO, Karenine Oliveira. O sofrimento e a dor como constituintes da beleza esportiva: reflexões para a educação. Holos, ano 31, v. 5, 2015. p.401-413.

CAILLOIS, Roger. Os jogos e os homens. Lisboa: Editora Cotovia, 1990.

DALLARI, Martha Maria. Corrida de rua: Um fenômeno sociocultural contemporâneo. São Paulo, 2009.

DIAS, Cleber. Corrida de rua no país do futebol. Recorde: Revista de História do Esporte, v. 10, n. 1, 2017. p. 1-32.

DUNNING, Eric; MAGUIRE, Joseph. As relações entre os sexos no esporte. Revista Estudos Feministas, v.5, n.2, 1997. p.1-24.

ELIAS, Norbert; DUNNING, Eric. A busca da excitação. Lisboa: Difel, 1992.

FONSECA. C. Quando cada caso NÃO é um caso: pesquisa etnográfica e educação. Revista Brasileira de Educação, São Paulo, 10, p. 58-78, 1999.

GEERTZ, Clifford. Interpretação das culturas. Rio de Janeiro: Livros Técnicos e Científicos, 1989.

Vozes, 1997.

O saber local: novos ensaios em antropologia interpretativa. Petrópolis:

GONÇALVES, Michelle Carreirão; VAZ, Alexandre Fernandez. Educação do corpo, dor, sacrifício: um estudo com competidores de atletismo. Revista Iberoamericana de Educación / Revista Ibero-americana de Educação, n. 58/1, 2012. p.1-10. 
GRATÃO, Otávio Augusto; ROCHA, Cláudio Miranda da. Dimensões da motivação para correr e para participar de eventos de corrida. R. bras. Ci. e Mov, v.24, n.3, 2016. p.90-102.

HUIZINGA, Johan. Homo Ludens: o jogo como elemento da cultura. 5. ed. São Paulo: Perspectiva, 2001.

LÉVI-STRAUSS, Claude. Introdução à obra de Marcel Mauss. In: MAUSS, Marcel. Sociologia e Antropologia. São Paulo: Cosacnify, 2003. p.11-46.

MARCELLINO, Nelson Carvalho. Lazer e Educação. 10. ed. Campinas: Papirus, 2003.

MASSON, Letícia Fernanda Feitosa. Corrida de rua: uma prática democrática. Dissertação de mestrado. Programa de Pós-graduação em Ciências do Movimento Humano da Universidade Metodista de Piracicaba (UNIMEP), 2016.

MAUSS, Marcel. Sociologia e Antropologia. São Paulo: Cosacnaify, 2003. ; HUBERT, Henri. Sobre o sacrifício. São Paulo: Cosacnaify, 2005.

MINAYO, Maria Cecília de Souza. O desafio da pesquisa social. In: MINAYO, Maria Cecília de Souza (Org.). Pesquisa social: teoria, método e criatividade. 21. ed. Rio de Janeiro: Vozes, 1994. P. 9-30.

OLIVEIRA, Saulo Neves de. Lazer sério e envelhecimento: explorando a carreira de corredores de longa distância em um grupo de corridas de rua no sul do Brasil. Tese de Doutorado. Programa de Pós-graduação em Educação, Faculdade de Educação da Universidade Federal do Rio Grande do Sul (UFRGS), 2016.

PINTO, Mauricio Rodriguez; ALMEIDA, Marco Bettine. As torcidas queer em campo: a emergência de grupos que questionam a homofobia e o machismo no futebol. Revista Brasileira de Estudos do Lazer, v.1, n.2, 2014. p. 105-116.

PURIM, Kátia Sheylla Malta; TITSKI, Ana Cláudia Kapp; BENTO, Paulo César Barauce; LEITE, Neiva. Lesões desportivas e cutâneas em adeptos de corrida de rua. Revista Brasileira de Medicina do Esporte, v.20, n. 4, 2014. p. 299-303.

ROJO, Jeferson Roberto; STAREPRAVO, Fernando Augusto; CANAN, Felipe; MEZZADRI, Fernando Marinho; SILVA, Marcelo Moraes e. Transformações no modelo de corridas de rua no Brasil: um estudo na "Prova Rústica Tiradentes". R. bras. Ci. e Mov, v. 25, n. 1, 2017a. p.19-28.

; STAREPRAVO, Fernando Augusto; MEZZADRI, Fernando Marinho; SILVA, Marcelo Moraes e. Corrida de rua: reflexões sobre o "universo" da modalidade. Revista Corpoconsciência, v. 21, n. 3, 2017b. p.82-96. 
SANCHO, Juana M.; HERRAIZ, Fernando; HERNANDEZ, Fernando; VIDIELLA, Judit. Masculinidade hegemônica, esportes e atividade física. Movimento, v.16, n.4, 2010. p.93-115.

SILVA, Cinthia Lopes da; HASSE, Manuela. Lazer e esportes: textos didáticos. Piracicaba: Editora Unimep, 2013.

\section{Endereço dos Autores:}

Cinthia Lopes da Silva

Universidade Metodista de Piracicaba

Rodovia do Açucar, km 156, n. 7000

Piracicaba - SP - 13.423-170

Endereço Eletrônico: cinthialsilva@uol.com.br

Ana Carolina Capellini Rigoni

Departamento de Ginástica - DG - Centro e Educação Física e Desportos - CEFD

Universidade Federal do Espírito Santo - UFES

Avenida Fernando Ferrari, 514 - Goiabeiras

Vitória - ES - 29.060-220

Endereço Eletrônico: anacarolinarigoni@yahoo.com.br

Luciene Ferreira da Silva

Faculdade de Ciências - Campus de Bauru

Av. Eng. Luiz Edmundo Carrijo Coube, 14-01 - Vargem Limpa

Bauru - SP - 17,0033-360

Endereço Eletrônico: silvalucienef@gmail.com

Marcelo de Farias Teixeira

Instituto Federal de Educação Ciência e Tecnologia do Norte de Minas Gerais

Campus Januária - Fazenda São Geraldo s/n - km 06 - Zona Rural

Januária - MG - 39.480-000

Endereço Eletrônico: marcellofat@bol.com.br 